\title{
$\alpha$-Cyclodextrin dimer complexes of dopamine and levodopa derivatives to assess drug delivery to the central nervous system: ADME and molecular docking studies
}

This article was published in the following Dove Press journal: International Journal of Nanomedicine

26 June 2012

Number of times this article has been viewed

\section{Sergey Shityakov \\ Jens Broscheit \\ Carola Förster}

Department of Anesthesiology and Critical Care, University of Würzburg, Würzburg, Germany
Correspondence: Carola Förster; Sergey Shityakov Department of Anesthesiology and Critical Care, University of Würzburg, 97080 Würzburg, Germany Email e_shityako_s@klinik.uni-wuerzburg.de

\begin{abstract}
This paper attempts to predict and emphasize molecular interactions of dopamine, levodopa, and their derivatives (Dopimid compounds) containing 2-phenyl-imidazopyridine moiety with the $\alpha$-cyclodextrin dimer in order to assess and improve drug delivery to the central nervous system. The molecular docking method is used to determine the energetic profiles, hydrogen bond formation, and hydrophobic effect of 14 host-guest complexes. The results show that the "chemical branching" represented by additional ethyl-acetate residue is energetically unfavorable and promotes a conformational shift due to the high root mean square deviation levels. This phenomenon is characterized by a low number of $\mathrm{H}$-bonds and a significant decrease of the host-guest hydrophobic potential surface. Finally, the overall docking procedure presents a powerful rationale for screening and analyzing various sets of promising drug-like chemical compounds in the fields of supramolecular chemistry, molecular sensing, synthetic receptors, and nanobiotechnology.
\end{abstract}

Keywords: dopamine, levodopa, Dopimid compounds, $\alpha-\mathrm{CD}$ dimer, molecular docking, complexation

\section{Introduction}

Molecular encapsulation of chemical compounds with cyclodextrins (CDs), a form of cone-shaped oligosaccharides, has drawn much attention in recent years for its ability to improve drug pharmacokinetic and pharmacodynamic properties and to potentiate biological effects. ${ }^{1,2}$ Therefore, experimental and theoretical methodologies investigating the structural features of CD-drug complexes, as well as their mechanisms of interaction, are of increasing importance. Only a few studies have reported that $\alpha$-and $\beta$-CDs are good binders for dopamine (3-hydroxytyramine, 3,4-dihydroxyphenethylamine [DA]), an important neurotransmitter that is widely distributed in the mammalian central nervous system (CNS). ${ }^{3-5}$

Newly synthesized amphiphilic $\alpha$-cyclodextrin esters have the potential to serve as DA carrier molecules ${ }^{36}$ and to facilitate drug delivery to the CNS. However, many CNS-active drugs, such as levodopa (L-3,4-dihydroxyphenylalanine [L-DOPA]) and its derivatives, are characterized by low or insufficient water solubility, oxidation, and decarboxylation reactivity with intestinal and blood enzymes. ${ }^{6,7}$

It is already known that a lack of DA in the brain is associated with the progressive neurological ailment known as Parkinson's disease. ${ }^{8}$ In this context, the effectiveness of DA and L-DOPA derivatives to treat this disorder would be highly compromised. 
Some attempts have been made to bypass these problems by formulation and complexation in $\mathrm{CD}$, and to promote drug absorption by extracting cholesterol and phospholipids from the membranes. ${ }^{9,36}$ Overall, the improvement of intestinal absorption of poorly soluble compounds by CDs is an important parameter because it allows these compounds to reach lipophilic areas in aqueous environments. ${ }^{10}$ In fact, a central hydrophobic channel of CD can encompass a chemical compound as a guest molecule and can produce a host-guest complex formation, thereby enhancing the solubility rate. ${ }^{11-14}$ On the other hand, CDs may protect guest molecules from chemical hydrolysis by diminishing their ability to bind to plasma proteins for analyzed substances. ${ }^{15}$ In this way, CDs can increase the plasma level of complexed drugs and, ultimately, increase their therapeutic effect.

The mechanisms that involve the interaction of hydrogen bonds are van der Waals' forces and the hydrophobic effect; these mechanisms are at the core of host-guest inclusion complexation. ${ }^{16}$ Considering the lipophilic interior of CDs, the binding ability of DA/L-DOPA derivatives is generally attributable to a hydrophobic interaction, and the conformational shape and size complementarities between these structures.

This study docked a new series of DA and L-DOPA derivatives with a tail-to-tail $\alpha-C D$ dimer to determine and characterize the supramolecular driving forces of the hostguest complexation, and to emphasize its ability to assess and improve drug delivery to the central nervous system.

\section{Computational methods}

The crystal holo-structure of a tail-to-tail $\alpha$-CD dimer with a monofunctional carboxylic acid was taken from the OpenCDLig, a free web application for sharing resources about cyclodextrin complexes. ${ }^{17}$ The aliphatic chain of the carboxylic acid was threaded through a $\alpha$-CD dimer, resulting in a 1:2 stoichiometry. ${ }^{32}$

DA and L-DOPA molecular structures were extracted from the PubChem database with reference codes CID_681 and CID_6047, respectively (Figure 1). The chemical formulas of the so-called Dopimid compounds (Figure 1) were obtained from a research article by Denora et al. ${ }^{27}$ The two-dimensional (2D) structures of these compounds were drawn using MarvinSketch software (ChemAxon, Budapest, Hungary). ${ }^{18}$ After the $2 \mathrm{D}$ sketches were converted into threedimensional (3D) images, explicit hydrogens were added and the structures were energetically minimized and recorded in PDB format. Log BB, human intestinal absorption (HIA), and plasma protein binding (PPB) parameters were predicted by the PreADMET workflow using the genetic functional approximation method. ${ }^{19}$ This strategy is based on the calculation of molecular descriptors, which involves dividing all compounds into training, validation, and external sets.

The octanol-water partition coefficient $(\log P)$ as a measure of molecular hydrophobicity was determined by the robust Molinspiration method (miLogP2.2, 2005) using the group contributions. These were obtained by fitting the experimental $\log P$ values with predicted ones for a training set of more than 12,000 drug-like compounds.

The hydrophobic cavity volume was calculated using the MOLCAD module that is integrated in the Sybyl-X 1.1 software (Tripos International, St Louis, MO). The binding site (Figure 2A) was detected in the $\alpha-C D$ dimer molecule using the PocketAnalyzer ${ }^{\mathrm{PCA}}$ program (Novartis Institutes for Biomedical Research, Horsham, UK). ${ }^{20}$ Before starting the molecular docking, the AutoDockTools software (Molecular Graphics Laboratory Department of Molecular Biology, MB-5 The Scripps Research Institute, La Jolla, CA). ${ }^{21}$ was used to optimize the guest compounds from the PDB files, add Gasteiger charges, assign polar hydrogen atoms, and set up rotatable bonds. Flexible molecular docking was applied to the center of the binding cavity with the AutoDock Vina (ADVina) docking engine (Molecular Graphics Laboratory) ${ }^{22}$ using the following Cartesian coordinates: $x=8.52 \AA, y=13.94 \AA$, $z=8.99 \AA$. A docking grid with a dimension of $25 \AA \times 25 \AA$ $\times 25 \AA$ was used. The ADVina output results represented the docking scores as Gibbs free energy of binding $(\Delta G)$, and were further converted to the predicted equilibrium constants $\left(\mathrm{K}_{\mathrm{c}}\right)$. The $\mathrm{K}_{\mathrm{c}}$ values for all the docked poses were calculated from the $\Delta \mathrm{G}$ values as follows: $\mathrm{K}_{\mathrm{c}}=\exp \left(\left[\Delta \mathrm{G}^{*} 1000\right] /\left[\mathrm{R}^{*} \mathrm{~T}\right]\right)$, where $\mathrm{R}$ (gas constant) is $1.98 \mathrm{cal}^{*}\left(\mathrm{~mol}^{*} \mathrm{~K}\right)^{-1}$ and $\mathrm{T}$ (room temperature) is 298.15 Kelvin. The molecular poses were analyzed with the PyMol AutoDock/Vina plug-in (Computational Biomolecular Dynamics Group, Max-Planck-Institute for Biophysical Chemistry, Göttingen, Germany) and the Visual Molecular Dynamics program (version 1.9; Theoretical and Computational Biophysics Group, Beckman Institute, Urbana, IL). In situ optimization and refinement of docking poses were performed with the Szybki program (OpenEye Scientific Software, Santa Fe, NM) using the Merck Molecular Force Field (MMFF94; Merck \& Co, Whitehouse Station, NJ) without the solvent effect. MMFF94-optimized geometries based on the atom types, energies, and their gradients were calculated and strictly validated against Merck's published dataset. ${ }^{23}$

Molecular graphics and visualization were performed with the Chimera software (Resource for Biocomputing, Visualization, and Informatic, San Francisco, CA). ${ }^{24}$ The 
<smiles>O=C(Cc1c(-c2ccc(Cl)cc2)nc2c(Cl)cc(Cl)cn12)NC(Cc1ccc(O)c(O)c1)C(=O)O</smiles><smiles>O=C(Cc1c(-c2ccc(Cl)cc2)nc2ccc(Cl)cn12)NC(Cc1ccc(O)c(O)c1)C(=O)O</smiles><smiles>O=C(Cc1c(-c2ccccc2)nc2ccc(Cl)cn12)NC(Cc1ccc(O)c(O)c1)C(=O)O</smiles><smiles>CCOC(=O)C(Cc1ccc(O)c(O)c1)NC(=O)Cc1c(-c2ccc(Cl)cc2)nc2c(Cl)cc(Cl)cn12</smiles><smiles>CCOC(=O)[C@H](Cc1ccc(O)c(O)c1)NC(=O)Cc1c(-c2ccc(Cl)cc2)nc2ccc(Cl)cn12</smiles><smiles>[3H]C(Cc1ccc(O)c(O)c1)C(=O)NC(Cc1c(-c2ccccc2)nc2c(Cl)cc(Cl)cn12)C(=O)OCC</smiles><smiles>CCOC(=O)C(Cc1ccc(O)c(O)c1)NC(=O)Cc1c(-c2ccccc2)nc2c(Cl)cccn12</smiles><smiles>O=C(Cc1c(-c2ccc(Cl)cc2)nc2c(Cl)cc(Cl)cn12)NCCc1ccc(O)c(O)c1</smiles><smiles>O=C(Cc1c(-c2ccc(Cl)cc2)nc2ccc(Cl)cn12)NCCc1ccc(O)c(O)c1</smiles><smiles>O=C(Cc1c(-c2ccccc2)nc2c(Cl)cc(Cl)cn12)NCCc1ccc(O)c(O)c1</smiles><smiles>O=C(Cc1c(-c2ccccc2)nc2ccc(Cl)cn12)NCCc1ccc(O)c(O)c1</smiles><smiles>NCCc1ccc(O)c(O)c1</smiles>

DA<smiles>N[C@@H](Cc1ccc(O)c(O)c1)C(=O)O</smiles>

L-DOPA

Figure I Chemical structure of DA, L-DOPA, and Dopimid compounds.

Abbreviations: DA, dopamine; L-DOPA, levodopa.

host-guest molecular hydrophobicity potential surface $\left(\mathrm{S}_{\mathrm{MHP}}\right)$ was calculated before (MMFF94-) and after (MMFF94+) the MMFF94 optimization (Tables 2 and 3) and hydrogen bonds were formed. This was achieved with the PLATINUM web tool (Ovchinnikov Institute of Bioorganic Chemistry, Russian Academy of Sciences, U1., Moscow, Russia) ${ }^{25}$ using the following equation: $\mathrm{S}_{\mathrm{MHP}}=\left(\mathrm{S}_{\text {buried }}-\mathrm{S}_{\mathrm{H} / \mathrm{H}}\right) /\left(\mathrm{S}_{\text {total }}\right)$, where $\mathrm{S}_{\mathrm{H} / \mathrm{H}}$ is the hydrophilic match surface, $S_{\text {buried }}$ is the contact (hydrophobic) surface, and $\mathrm{S}_{\text {total }}$ is the total ligand surface. 


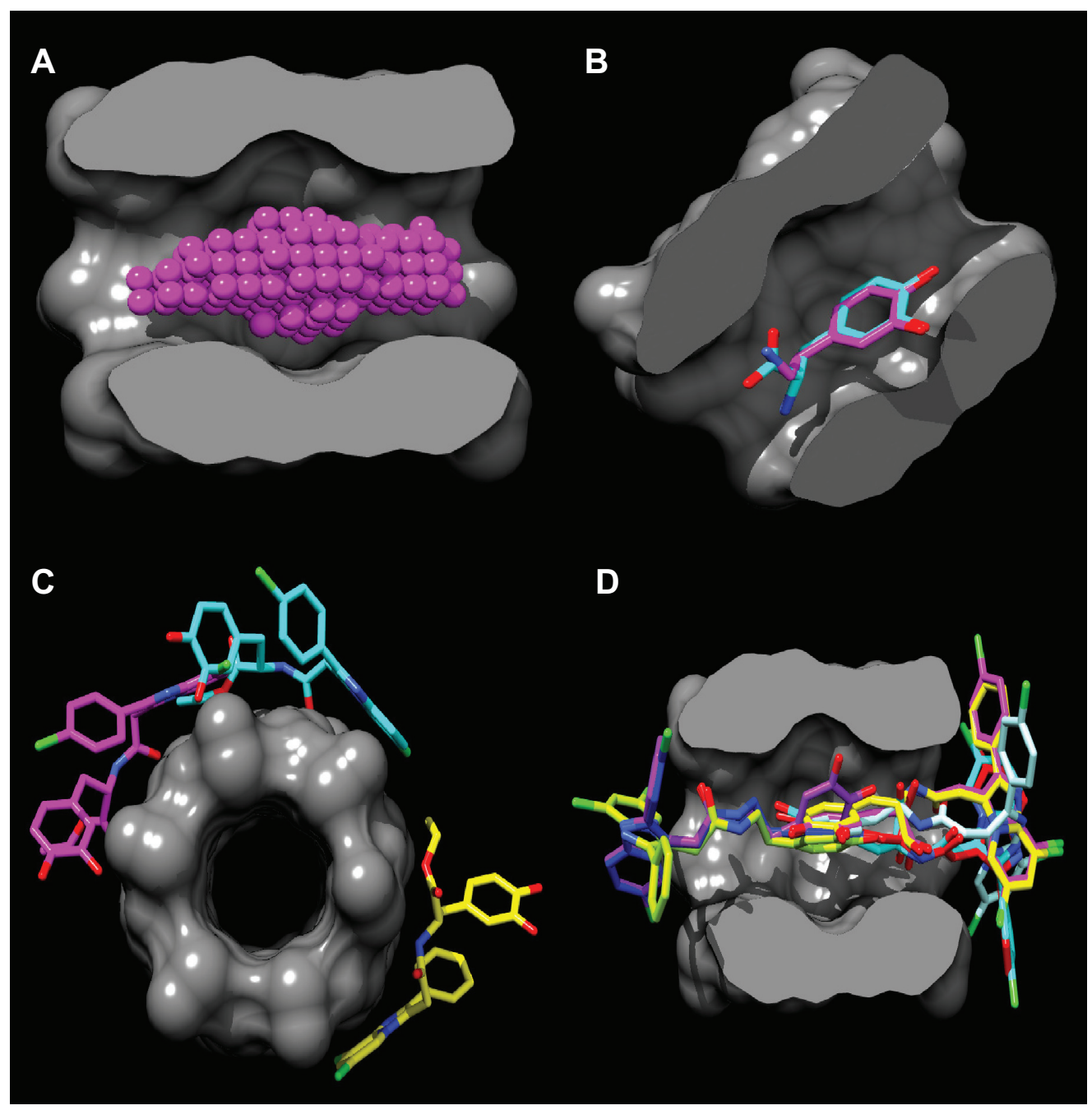

Figure 2 Binding site in the $\alpha-C D$ dimer cavity $(\mathbf{A})$ is detected with the PocketAnalyzer ${ }^{\mathrm{PCA}}$ (Novartis Institutes for Biomedical Research, Horsham, UK). (B) Shows the docking of the DA and L-DOPA molecules and the mode of hydrophobic moiety (2,3-dihydroxyphenyl) interaction with the $\alpha$-CD dimer. Out-channel docking poses are exposed outside the $\alpha-C D$ binding site $(\mathbf{C})$, while in-channel binding modes (D) are docked inside the cavity, highlighting the phenomenon of chiral docking. The molecular surface is divided by the frontal plane to visualize a binding channel of the host. Hydrogen atoms are omitted for clarity.

Abbreviations: $\alpha$-CD, $\alpha$-cyclodextrin; DA, dopamine; L-DOPA, levodopa.

To assign $\mathrm{S}_{\mathrm{MHP}}$ correctly, the hydrophobic properties of a host and its guest were projected onto the molecular surface of the host. Statistical analyses were performed using a linear regression analysis followed by a $3 \mathrm{D}$ graphic representation using GraphPad Prism v.4. for Windows (GraphPad Software, San Diego, CS) and SigmaPlot 11.0 (Systat Software GmbH, Germany). The differences were considered statistically significant at $P<0.0001$.

\section{Results and discussion}

Evaluation of physicochemical properties and the blood-brain barrier (BBB) permeability rates of guest compounds

The calculated $\log P$ and $\log$ BB values for DA, L-DOPA, and Dopimid compounds were obtained to evaluate their ability to act at the CNS level and possess optimal BBB permeation properties (Table 1). Denora et al have shown that Dopimid compounds 1-12 include $\log P$ values in the range of 3.03-5.13, which is similar to our data (1.72-5.47), which was calculated by the Molinspiration algorithm. These results indicate the lipophilic character of the examined compounds, which was considered high enough to cross the BBB with the exception of DA and L-DOPA ( $\log P-0.05$ and -2.19$)$. However, the $\log P$ has proven insufficient for the accurate evaluation of $\mathrm{BBB}$ permeation, since it correlates poorly with the $\log \mathrm{BB}$.

According to the CNS \pm activity classification for different chemical datasets, ${ }^{26}$ compounds with $\log \mathrm{BB}>0$ can cross the $\mathrm{BBB}$ readily, while drugs with $\log \mathrm{BB}<0$ cannot. Therefore, only Dopimid compounds 9-12 ( $\log$ BB $0.01-0.4$ ) 
Table I Molecular properties of chemical compounds

\begin{tabular}{|c|c|c|c|c|c|c|}
\hline Compound & $\begin{array}{l}\Delta \mathbf{G} \\
\left(\mathrm{kcal} * \mathrm{~mol}^{-1}\right)\end{array}$ & $\begin{array}{l}K_{c} \\
\mu M\end{array}$ & $\begin{array}{l}\text { HIA } \\
\%\end{array}$ & $\log B B$ & $\begin{array}{l}\text { PPB } \\
\%\end{array}$ & $\log P$ \\
\hline $\mathrm{DA}$ & -6.1 & 32.54 & 82.61 & -0.31 & 14.29 & -0.05 \\
\hline L-DOPA & -6.4 & 19.57 & 59.66 & -0.36 & 2.96 & -2.19 \\
\hline I & -7.4 & 3.59 & 94.99 & -0.51 & 94.32 & 3.02 \\
\hline 2 & -7.3 & 4.26 & 94.11 & -0.67 & 91.17 & 2.42 \\
\hline 3 & -7.3 & 4.26 & 94.11 & -0.82 & 90.76 & 2.35 \\
\hline 4 & -7.0 & 7.08 & 93.38 & -0.88 & 89.89 & 1.74 \\
\hline 5 & -4.4 & 579.5 & 95.92 & -0.76 & 90.39 & 5.47 \\
\hline 6 & -4.5 & 489.2 & 95.19 & -0.12 & 88.17 & 4.87 \\
\hline 7 & -4.3 & 686.5 & 95.19 & -0.24 & 87.91 & 4.79 \\
\hline 8 & -5.6 & 75.90 & 94.27 & -0.45 & 87.84 & 4.18 \\
\hline 9 & -7.4 & 3.59 & 95.36 & 0.40 & 93.72 & 5.25 \\
\hline 10 & -7.6 & 2.56 & 94.93 & 0.27 & 90.70 & 4.64 \\
\hline II & -7.5 & 3.04 & 94.93 & 0.17 & 90.47 & 4.54 \\
\hline 12 & -7.4 & 3.59 & 94.28 & 0.01 & 90.99 & 3.96 \\
\hline
\end{tabular}

Abbreviations: $\Delta G$, Gibbs free energy of binding; HIA, human intestina absorption; $\mathrm{K}_{c}$, predicted equilibrium constant; PPB, plasma protein binding; DA dopamine; L-DOPA, levodopa.

should be considered as BBB-permeants; these results deviate from the previously shown data. ${ }^{27}$ The authors provide the $\log \mathrm{BB}$ distribution values in a range from -0.57 to -1.24 for the examined derivatives, which indicates the BBB impermeability prerequisites. The experimental log BB value for L-DOPA is approximately twofold lower than the predicted one ( -0.77 versus -0.36$)$, which is probably due to P-g efflux mechanism' ${ }^{28}$ influence on metabolic factors, or other experimental difficulties such as compound extraction and purification. The discrepancies of the $\log \mathrm{BB}$ prediction

Table 2 Predicted parameters for MMFF94- conformational set

\begin{tabular}{llllll}
\hline Compound & $\begin{array}{l}\mathbf{H} \text {-bonds } \\
(\mathbf{n})\end{array}$ & $\mathbf{S}_{\mathbf{H} / \mathbf{H}}$ & $\mathbf{S}_{\text {buried }}$ & $\mathbf{S}_{\text {total }}$ & $\mathbf{S}_{\text {MHP(MMFF94-) }}$ \\
\hline DA & 5 & 68.92 & 155.31 & 166.07 & 0.52 \\
L-DOPA & 9 & 91.58 & 173.73 & 185.76 & 0.44 \\
I & 6 & 38.04 & 253.03 & 425.89 & 0.50 \\
2 & 6 & 36.90 & 240.76 & 370.18 & 0.55 \\
3 & 6 & 38.16 & 244.55 & 379.93 & 0.54 \\
4 & 5 & 40.63 & 241.32 & 371.88 & 0.54 \\
5 & 5 & 22.15 & 123.10 & 387.65 & 0.26 \\
6 & 4 & 21.27 & 140.57 & 394.49 & 0.30 \\
7 & 6 & 31.46 & 130.19 & 382.40 & 0.26 \\
8 & 2 & 21.39 & 232.21 & 407.53 & 0.52 \\
9 & 4 & 11.65 & 222.02 & 362.15 & 0.58 \\
10 & 5 & 8.99 & 224.24 & 358.79 & 0.60 \\
11 & 6 & 19.05 & 217.08 & 356.26 & 0.56 \\
12 & 4 & 14.56 & 222.08 & 354.49 & 0.59 \\
\hline
\end{tabular}

Notes: $S_{M H P}=\left(S_{\text {buried }}-S_{H H H}\right) /\left(S_{\text {totan }}\right)$, where $S_{H / H}$ is the hydrophilic match surface, $S_{\text {buried }}$ is the contact (hydrophobic) surface, and $S_{\text {total }}$ is the total ligand surface.

Abbreviations: DA, dopamine; L-DOPA, levodopa; MMFF94, Merck Molecular Force Field (Merck \& Co, Whitehouse Station, NJ); MMFF94-, before MMFF94 optimization; $\mathrm{n}$, number.
Table 3 Predicted parameters for MMFF94+ conformational set

\begin{tabular}{llllll}
\hline Compound & $\begin{array}{l}\text { H-bonds } \\
(\mathbf{n})\end{array}$ & $\mathbf{S}_{\mathbf{H} / \mathrm{H}}$ & $\mathbf{S}_{\text {buried }}$ & $\mathbf{S}_{\text {total }}$ & $\mathbf{S}_{\text {MHP(MMFF94+) }}$ \\
\hline DA & 5 & 71.58 & 156.45 & 164.68 & 0.52 \\
L-DOPA & 4 & 85.63 & 174.55 & 188.54 & 0.47 \\
I & 3 & 74.75 & 203.03 & 381.96 & 0.33 \\
2 & 4 & 25.25 & 233.29 & 378.34 & 0.54 \\
3 & 6 & 98.04 & 232.34 & 389.49 & 0.34 \\
4 & 3 & 28.99 & 208.67 & 374.68 & 0.47 \\
5 & 1 & 24.43 & 105.31 & 411.50 & 0.20 \\
6 & 1 & 17.78 & 118.10 & 422.57 & 0.24 \\
7 & 3 & 70.13 & 102.85 & 410.57 & 0.08 \\
8 & 2 & 22.72 & 209.30 & 416.51 & 0.45 \\
9 & 3 & 74.11 & 218.03 & 379.11 & 0.38 \\
10 & 2 & 11.20 & 215.25 & 368.15 & 0.55 \\
II & 4 & 14.94 & 220.00 & 375.44 & 0.55 \\
12 & 4 & 16.46 & 215.50 & 368.48 & 0.54 \\
\hline
\end{tabular}

Notes: $S_{M H P}=\left(S_{\text {buried }}-S_{H / H}\right) /\left(S_{\text {total }}\right)$, where $S_{H / H}$ is the hydrophilic match surface, $\mathrm{S}_{\text {buried }}$ is the contact (hydrophobic) surface, and $\mathrm{S}_{\text {tot }}$ is the total ligand surface.

Abbreviations: DA, dopamine; L-DOPA, levodopa; MMFF94, Merck Molecular Force Field (Merck \& Co, Whitehouse Station, NJ); MMFF94+, after MMFF94 optimization; n, number.

can be explained by the fact that the authors used a simplified Clark's model approach that relates this coefficient to the polar surface area descriptor. ${ }^{29}$

PPB and human intestinal absorption rates for Dopimid compounds were more than $80 \%$ and $90 \%$, respectively. However, the parameters for DA and L-DOPA were significantly reduced, particularly for PPB. As a control, the PPH and HIA values for L-DOPA $(<10 \% \text { and } 40 \% \pm 19 \%)^{30,31}$ closely matched our predicted results (2.96\% and 59.66\%).

\section{Analysis of ADVina docking results and binding affinities of $\alpha-C D$ dimer complexation}

In terms of the molecular docking studies, we set out to analyze the host-guest complexation mechanism of $\alpha-C D$ dimer, DA, L-DOPA molecules, and Dopimid compounds by measuring the binding affinities. Since it engulfs most of the guest molecule, the $\alpha-C D$ dimer can be considered more suitable for molecular docking than its monomer, which has a deep $346.604 \AA^{3}$ hydrophobic cavity volume and an approximate length of $15.6 \AA\left(174 \AA^{3}\right.$ and $7.8 \AA$ for monomer). The dimer was kept in the form of a single conformation as provided in the crystal structure, ${ }^{32}$ since it is rather rigid, and the flip-flop hydrogen bonds between the secondary hydroxyl groups restrict the flexibility of the hydrophobic core. The cavity size of the $\alpha$-CD dimer must be large enough to allow the guest molecule to enter by keeping the guest molecule inside the cavity via a high stability constant, which achieves relatively low dissociation of the 
inclusion. Furthermore, it does not implement significant conformational alterations when complexing to different chemical compounds.

A standard molecular docking procedure yielded two main outcomes: a conformational sampling (docking pose) of guest molecules within the host binding site, and a score approximation function $(\Delta \mathrm{G})$ representing the strength of host-guest interaction. All docking poses were visually inspected to rank the different host conformations of the complex.

As shown in Figure 2B, the location of the DA and L-DOPA docking poses is roughly defined in the middle of the $\alpha-C D$ dimer, where the binding site is positioned. The site is stabilized by intramolecular H-bonds between the adjacent secondary hydroxyl-groups with a mean distances of $2.78 \AA$. The $\alpha$-CD dimer encompasses the whole DA, L-DOPA molecules, and the 2,3-dihydroxyphenyl moiety of the Dopimid compounds, while the lipophilic 2-phenyl-imidazoperidyne moiety is exposed outside the $\alpha-C D$ binding channel. However, this hydrophobic moiety could serve as a transporter system to increase DA and L-DOPA brain concentrations by considering the high BBB permeation of the phenyl-imidazopiridyne derivatives. ${ }^{33}$

Compounds 5, 6, and 7 were docked outside the $\alpha-C D$ dimer binding channel, representing "out-channel" noninclusion complexation with maximal $\Delta \mathrm{G}$ values of $-4.4,-4.5$, and $-4.3 \mathrm{kcal}^{*} \mathrm{~mole}^{-1}$, respectively (Figure $2 \mathrm{C}$ ). The rest of the guest molecules were docked "in-channel" through the entry site at the narrow 6-rim of the dimer where primary hydroxyl groups exist (Figure 2D). Meanwhile, guest lipophilic phenyl groups fit better into a wider 2, 3-rim of the relatively hydrophobic cavity. Interestingly, "in-channel" docking modes were subdivided into the R-site docking for DA, L-DOPA, compounds 1-4, 8, 9, and the S-site docking for compounds 10-12, indicating the "chiral" character of this type of host-guest complexation.

Dopimid compounds 9, 10, and 11 were associated with the best binding modes, which represents the minimal $\Delta \mathrm{G}$ because of the strong binding affinity and intermolecular force between the host and its guest.

\section{Conformational analysis of Dopimid molecules and docking poses}

Dopimid compounds contain different numbers of chloride radical residues and functional groups (hydroxyl, carboxyl, and carbonyl groups) as a result of hydroxylation, chlorination, and other chemical modifications of the initial structure such as N-(2-phenylethyl)-2-\{2-phenylimidazo[1,2-a] pyridine-3-yl $\}$ acetamide (reference molecule). To emphasize the differences between the minimized Dopimid molecules and the docking poses, we aligned these compounds with the initial structure and measured the root-mean-square deviation (RMSD) values. To achieve this task, the Dopimid modifications were preliminarily removed to reach a proper atomic pair-wise matching. Prior to the rigid alignment, Dopimid docking poses were subjected to in situ MMFF94 refinement to optimize the noncovalent host-guest interactions within the $\alpha-\mathrm{CD}$ dimer active site. Although the parameters in the force field are derived initially from computational data, they perform well for a wide range of organic chemistry calculations. ${ }^{34}$ MMFF94-docking poses are associated with the highest level of deviation rates. The RMSD values were even more prominent at compounds 5, 6, and 7 compared to the minimized Dopimid control substances (Figure 3). These compounds
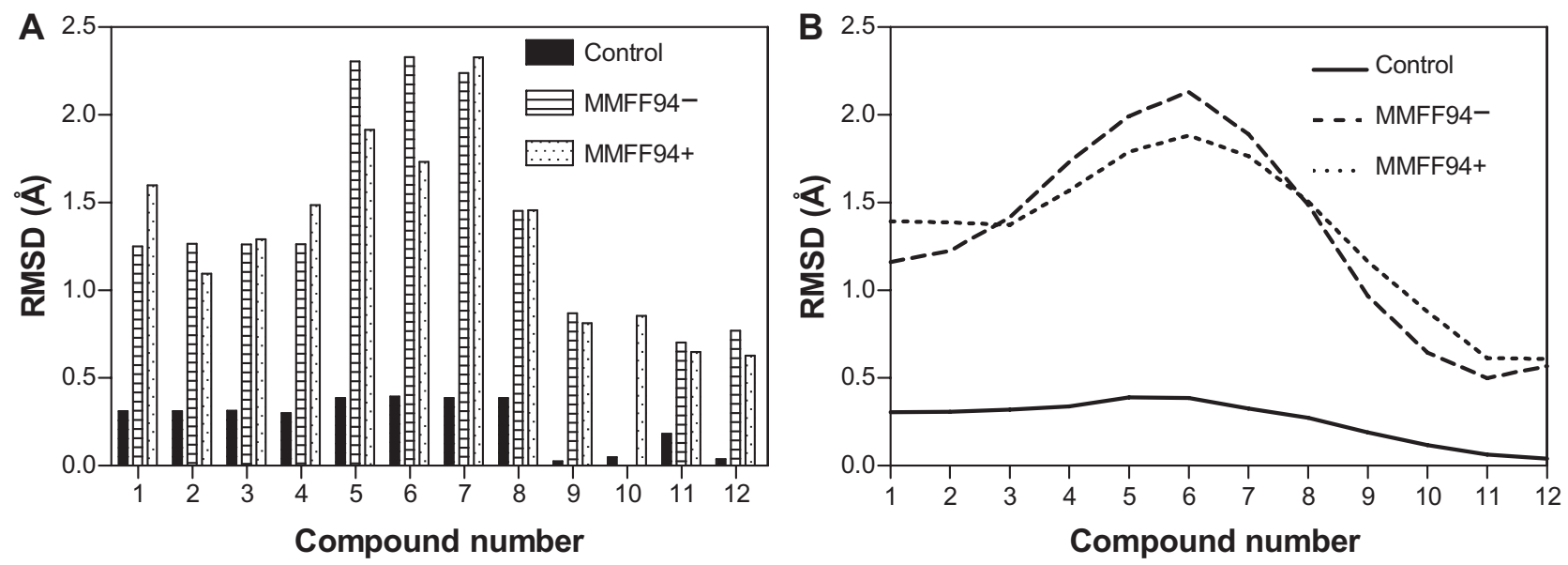

Figure 3 Reported guest RMSD values for Dopimid compound (rigid alignment was performed on the reference molecule) (A). Data smoothing was utilized to produce a fitting curve for the RMSD comparison (B).

Abbreviations: MMFF94, Merck Molecular Force Field (Merck \& Co, Whitehouse Station, NJ); MMFF94-, before MMFF94 optimization; MMFF94+, after MMFF94 optimization; RMSD, root-mean-square deviation. 
A

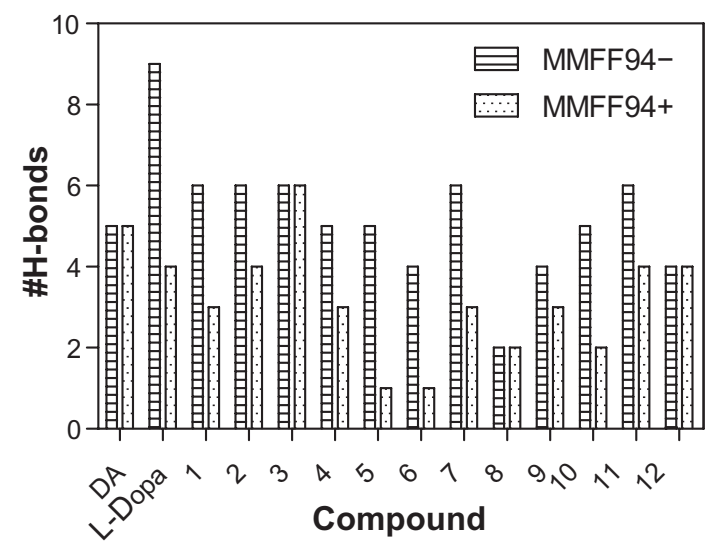

B

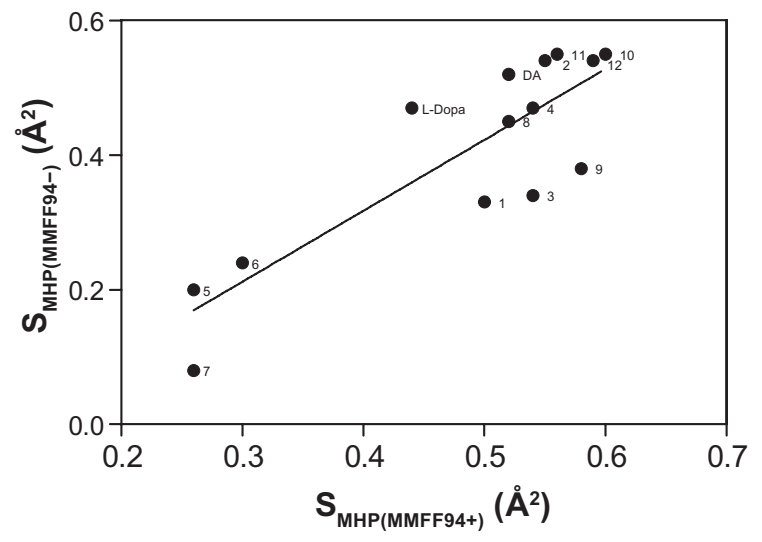

C

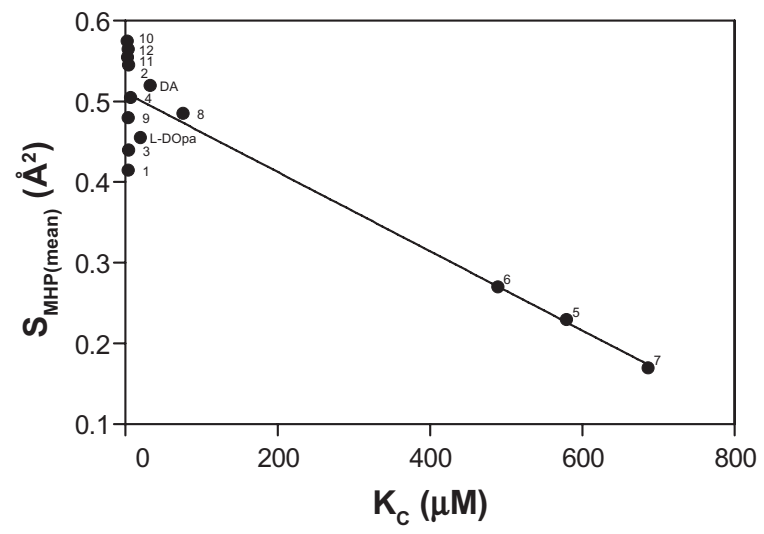

Figure $4 \mathrm{H}$-bond formation before and after the MMFF94 optimization $(\mathbf{A})$. Relationship between calculated hydrophobic descriptors $(\mathbf{B})$ and $\mathrm{K}_{\mathrm{c}}$ values $(\mathbf{C})$ using the linear regression analysis to determine a clustering for examined chemical compounds.

Note: $\mathrm{S}_{\mathrm{MHP}}=\left(\mathrm{S}_{\text {buried }}-\mathrm{S}_{\mathrm{H} / \mathrm{H}}\right) /\left(\mathrm{S}_{\text {total }}\right)$, where $\mathrm{S}_{\mathrm{H} / \mathrm{H}}$ is the hydrophilic match surface, $\mathrm{S}_{\text {buried }}$ is the contact (hydrophobic) surface, and $\mathrm{S}_{\text {total }}$ is the total ligand surface.

Abbreviations: DA, dopamine; $K_{c}$, predicted equilibrium constant; L-DOPA, levodopa; MMFF94, Merck Molecular Force Field (Merck \& Co, Whitehouse Station, NJ); MMFF94-, before MMFF94 optimization; MMFF94+, after MMFF94 optimization.

have additional ethyl-acetate residue in their structure that might contribute to the conformational shift that is the result of "chemical branching." At this point, the chemical branching is energetically unfavorable; it restricts the conformational shape of the guest molecules and prevents them from integrating into the $\alpha-C D$ dimer active channel. The restriction factor might be the insufficient diameter of the $\alpha$-CD inner cavity (5.7 $\AA$ ), which is less than the other cyclodextrins (7.8 $\AA$ for $\beta$-CD and $9.8 \AA$ for $\gamma$-CD, respectively).

\section{Estimation of hydrogen bonding and hydrophobic effect for $\alpha-C D$ dimer complexes}

The mechanisms of noncovalent interaction in host-guest complexes cover dipolar, ionic interactions, hydrogen bonding, van der Waals interactions, and so on. Nevertheless, the driving force of inclusion complexation is hydrophobic interaction and the host-guest complementary match, which are mainly attributed to the molecular shape. ${ }^{35}$
The PLATINUM methodology was applied to investigate if the hydrogen bonding and hydrophobic forces have an impact on the complexation mechanism. H-bond formations were established for all the analyzed compounds (Figure 4A) and represented different configurations observed in the dataset including $\mathrm{H}$-bonds between the host-guest functional groups (amino, hydroxyl, and carbonyl groups). Figure 4A demonstrates that the corresponding Dopimid compounds, such as 5 and 6 , have shown the minimal number of $\mathrm{H}$-bonds with the $\alpha-\mathrm{CD}$ dimer after MMFF94 refinement as an outcome of the unfavorable energetic profile and the "out-channel" docking. This holds true for the same compounds as well as compound 7; the calculated $\mathrm{S}_{\mathrm{MHC}}$ (MMFF94-/MMFF94+/mean) variables would also give the minimal measurements (Figure 4B and C). Consequently, the obtained $\mathrm{S}_{\mathrm{MHC}(\mathrm{MMFF} 94-)}, \mathrm{S}_{\mathrm{MHC}(\mathrm{MMFF} 94+)}, \mathrm{S}_{\mathrm{MHC}(\text { mean })}$ and equilibrium constants $\left(\mathrm{K}_{\mathrm{c}}\right)$ represented a relationship of correlation by a linear regression analysis with reliable statistics $\left(r^{2}=0.73\right.$ [0.87], $\mathrm{F}=32.56$ [81.29], $\left.\mathrm{n}=14\right)$, and 


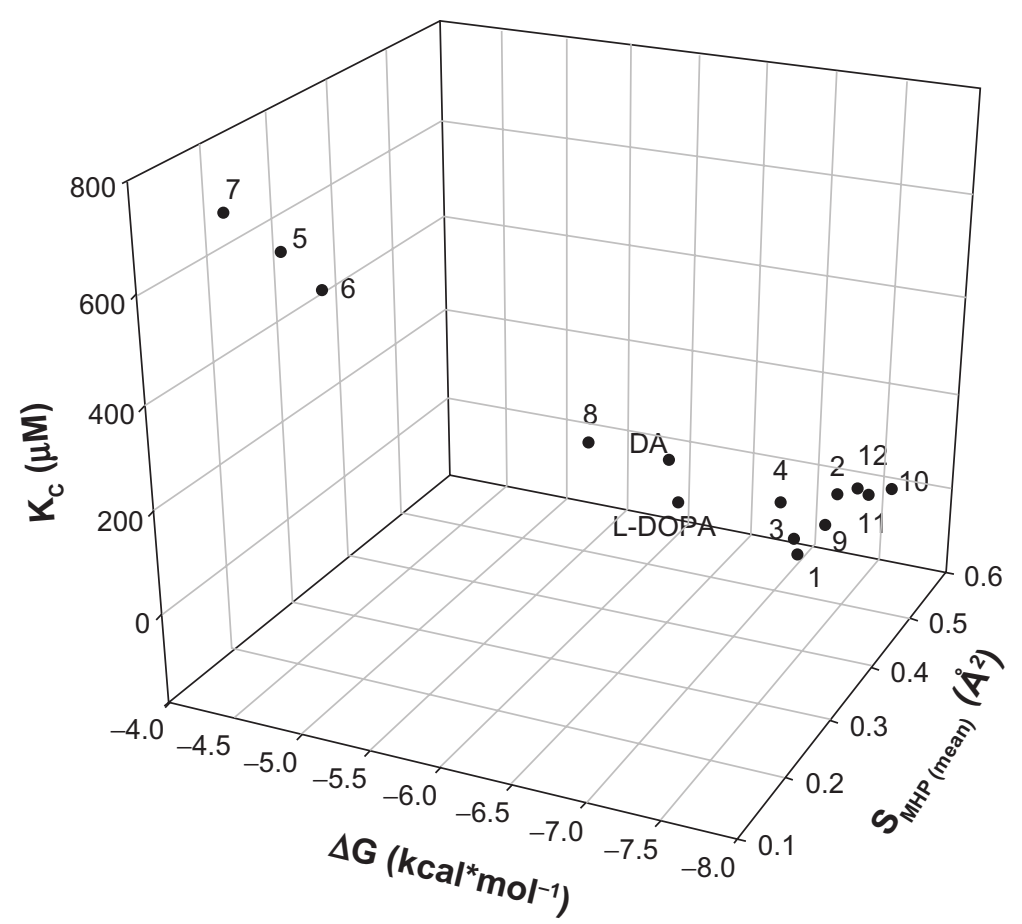

Figure 5 3D dot plot-visualization for the compounds reported in Table I. The distribution of the cluster formation is based on the energy function, equilibrium constant, and hydrophobicity.

Notes: $\mathrm{S}_{\mathrm{MHP}}=\left(\mathrm{S}_{\text {buried }}-\mathrm{S}_{\mathrm{H} / \mathrm{H}}\right) /\left(\mathrm{S}_{\text {total }}\right)$, where $\mathrm{S}_{\mathrm{H} / \mathrm{H}}$ is the hydrophilic match surface, $\mathrm{S}_{\text {buried }}$ is the contact (hydrophobic) surface, and $\mathrm{S}_{\text {total }}$ is the total ligand surface. Abbreviations: $\Delta \mathrm{G}$, Gibbs free energy of binding; $\mathrm{DA}$, dopamine; $\mathrm{K}_{c}$, predicted equilibrium constant; L-DOPA, levodopa.

$P<0.0001$. Figure 5 shows that of the 14 guest molecules, eight landed in one major cluster (compounds 1, 2-4, 9-12); and the rest formed two minor clusters comprising three substances each: compounds 5-7 and DA, L-DOPA, and compound 8 . The clustering of the chemical compounds shows that the distribution rate occurs in an MHP-dependant manner and that high levels of $\Delta \mathrm{G}$ and $\mathrm{K}_{\mathrm{c}}$ correlate with low levels of the $\mathrm{S}_{\mathrm{MHP}}$ parameters.

\section{Conclusion}

This study presents a molecular docking strategy to analyze the inclusion complexation of DA and L-DOPA derivatives enhanced by an appropriate 2-phenyl-imidazopyridine moiety using a $\alpha$-CD dimer. This technique makes it possible to obtain conformational geometric structures of the hostguest inclusion complexes with docking energies. The guest molecules inside the immobilized $\alpha$-CD dimer produced encapsulation via their size and shape complementary adaptation to a hydrophobic cavity of the dimer.

The 2-phenyl-imidazolpyridine moiety improves the lipophilicity of the Dopimid compounds and, partly, the $\log$ BB parameters of the Dopimid compounds. However, it has a negative effect on PPB and human intestinal absorption. Chemical branching is characterized by a low number of $\mathrm{H}-$ bond formations and a significant decrease in the hydrophobic potential surface $\left(\mathrm{S}_{\mathrm{MHP}}\right)$. From the results mentioned above, we can conclude that the ethyl-acetate residues for Dopimid compounds 5, 6, and 7 are involved in the conformational shift with very high values of $\Delta \mathrm{G}$ and $\mathrm{K}_{\mathrm{c}}$. Therefore, a combination of host-guest hydrophobic interactions with energetic profiles is a novel aspect that allows more rational formulation prerequisites for applications in the supramolecular chemistry of cyclodextrins.

\section{Acknowledgments}

The authors are grateful to the IZKF (Interdisziplinäres Zentrum für Klinische Forschung der Universität Würzburg) and the BMBF (Bundesministerium für Bildung und Forschung) for their support of this work by providing grants (BMBF01, EO1004) to Carola Förster.

\section{Disclosure}

The authors report no conflicts of interest in this work.

\section{References}

1. Szejtli J. Cyclodextrins and their Inclusion Complexes. Budapest: Akadémiai Kiadó; 1982.

2. Pitha J, Szente L, Szejtli J. Molecular encapsulation of drugs by cyclodextrins and congeners. In: Bruck SD, editor. Controlled Drug Delivery. Vol 1. Boca Raton, FL: CRC Press; 1983:124-148.

3. Szejtli J. Cyclodextrin Technology. Dordrecht: Kluwer Academic Press; 1988. 
4. Gao ZN, Wen XL, Li HL. Study of the inclusion complexes of catecholamines with b-cyclodextrin by cyclic voltammetry. Pol J Chem. 2002;76(7):1001-1007.

5. Fukuda T, Maeda Y, Kitano H. Stereoselective inclusion of DOPA derivatives by a self-assembled monolayer of thiolated cyclodextrin on a gold electrode. Langmuir. 1999;15(5):1887-1890.

6. Di Stefano B, Mosciatti G, Cingolani M, et al. Dimeric L-Dopa derivatives as potential prodrugs. Biorg Med Chem. 2001;11:1085-1088.

7. Wang H, Lee J, Tsai M, Lu H, Hsu W. Synthesis and pharmacological activities of a novel tripeptide mimetic dopamine prodrug. Biorg Med Chem. 1995;5:2195-2198.

8. Li Y, Huang X, Chen Y, Wang L, Lin X. Simultaneous determination of dopamine and serotonin by use of covalent modification of 5-hydroxytryptophan on glassy carbon electrode. Microchimica Acta. 2009;164(1-2):107-112.

9. Irie T, Uekama K. Pharmaceutical application of cyclodextrins: Toxycological issues and safety evaluation. J Pham Sci. 1997;86(2): $147-162$.

10. Irie T, Tsunenari Y, Uekama K, Josef P. Effect of bile on the intestinal absorption of $\alpha$-cyclodextrin in rats. Int J Pharm. 1988;43(1-2): $41-44$.

11. Loftson T, Brewster ME. Pharmaceutical applications of cyclodextrins. 1. Drug solubilization and stabilization. J Pharm Sci. 1996; 85:1017-1025.

12. Connors KA. The stability of cyclodextrin complexes in solution. Chem Rev. 1997;97:1325-1357.

13. Uekema K, Hirayama F, Irie T. Cyclodextrin drug carrier systems. Chem Rev. 1998;98:2045-2076.

14. Stella VJ, Rajewski RA. Cyclodextrins: their future in drug formulation and delivery. Pharm Res. 1997;14:556-567.

15. Frijlink HW, Franssen EJ, Eissens AC, Oosting R, Lerk CF, Meijer DK. The effects of cyclodextrins on the disposition of intravenously injected drugs in the rat. Pharm Res. 1991;8(3):380-384.

16. Steed JW, Turner DR, Wallace K. Core Concepts in Supramolecular Chemistry and Nanochemistry. Bognor Regis: John Wiley \& Sons, Ltd; 2007.

17. Esposito R, Ermondi G, Caron G. OpenCDLig: a free web application for sharing resources about cyclodextrin/ligand complexes. J Comput Aided Mol Des. 2009;23(9):669-675.

18. Pirok G, Maté N, Varga J, et al. Making "real" molecules in virtual space. J Chem Inf Model. 2006;46(2):563-568.

19. Rogers D, Hopfinger AJ. Application of genetic function approximation to quantitative structure-activity relationships and quantitative structure-property relationships. J Chem Inf Comput Sci. 1994;34(4): $854-866$.

20. Craig IR, Pfleger C, Gohlke H, Essex JW, Spiegel K. Pocket-space maps to identify novel binding-site conformations in proteins. $J$ Chem Inf Model. 2011;51(10):2666-2679.

21. Morris GM, Huey R, Lindstrom W, et al. AutoDock4 and AutoDockTools4: Automated docking with selective receptor flexibility. J Comput Chem. 2009;30(16):2785-2791.
22. Trott O, Olson AJ. AutoDock Vina: improving the speed and accuracy of docking with a new scoring function, efficient optimization, and multithreading. J Comput Chem. 2010;31(2):455-461.

23. Wlodek S, Skillman AG, Nicholls A. Ligand entropy in gas-phase, upon solvation and protein complexation. Fast estimation with Quasi-Newton Hessian. J Chem Theory Comput. 2010;6(7):2140-2152.

24. Pettersen EF, Goddard TD, Huang CC, et al. UCSF Chimera a visualization system for exploratory research and analysis. J Comput Chem. 2004;25(13):1605-1612.

25. Pyrkov TV, Chugunov AO, Krylov NA, Nolde DE, Efremov RG. PLATINUM: a web tool for analysis of hydrophobic/hydrophilic organization of biomolecular complexes. Bioinformatics. 2009;25(9): 1201-1202.

26. Ajay, Bemis GW, Murcko MA, Designing libraries with CNS activity. J Med Chem. 1999;42(24):4942-4951.

27. Denora N, Laquintana V, Lopedota A, et al. Novel L-Dopa and dopamine prodrugs containing a 2-phenyl-imidazopyridine moiety. Pharm Res. 2007;24(7):1309-1324.

28. Soares-Da-Silva P, Serrão MP. Outward transfer of dopamine precursor L-3,4-dihydroxyphenylalanine (L-dopa) by native and human P-glycoprotein in LLC-PK(1) and LLC-GA5 col300 renal cells. J Pharmacol Exp Ther. 2000;293(2):697-704.

29. Clark DE. Rapid calculation of polar molecular surface area and its application to the prediction of transport phenomena. 2. Prediction of blood-brain barrier penetration. J Pharm Sci. 1999;88(8): 815-821.

30. Seyffart G. Drug dosage in Renal Insufficiency. Berlin: Springer-Verlag $\mathrm{GmbH} ; 1991$.

31. Lennernäs H, Nilsson D, Aquilonius SM, Ahrenstedt O, Knutson L, Paalzow LK. The effect of L-leucine on the absorption of levodopa, studied by regional jejunal perfusion in man. Br J Clin Pharmacol. 1993;35(3):243-250.

32. Rodríguez-Llamazares S, Yutronic N, Jara P, Englert U, Noyong M, Simon U. The structure of the first supramolecular $\alpha$-cyclodextrin complex with an aliphatic monofunctional carboxylic acid. Eur Journ Org Chem. 2007:4298-4300.

33. Durand A, Thénot JP, Bianchetti G, Morselli PL. Comparative pharmacokinetic profile of two imidazopyridine drugs: zolpidem and alpidem. Drug Metab Rev. 1992;24(2):239-266.

34. Halgren TA. Merck molecular force field. I. Basis, form, scope, parameterization, and performance of MMFF94. J Comput Chem. 1996;17(5-6):490-519.

35. Lehn JM. Supramolecular chemistry - scope and perspectives molecules, supermolecules, and molecular devices (Nobel Lecture). Angew Chem Int Ed Engl. 1988;27(1):89-112.

36. Seyedi SM, Sadeghian H, Jabbari A, Assadieskandar A, Momeni H. Synthesis of new series of $\alpha$-cyclodextrin esters as dopamine carrier molecule. Bioorg Med Chem. 2011;19(14):4307-4311.
International Journal of Nanomedicine

\section{Publish your work in this journal}

The International Journal of Nanomedicine is an international, peerreviewed journal focusing on the application of nanotechnology in diagnostics, therapeutics, and drug delivery systems throughou the biomedical field. This journal is indexed on PubMed Central,

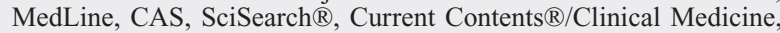

\section{Dovepress}

Journal Citation Reports/Science Edition, EMBase, Scopus and the Elsevier Bibliographic databases. The manuscript management system is completely online and includes a very quick and fair peer-review system, which is all easy to use. Visit http://www.dovepress.com/ testimonials.php to read real quotes from published authors. 